\title{
A dampened land use change climate response towards the tropics
}

\author{
M. K. van der Molen • B. J. J. M. van den Hurk • \\ W. Hazeleger
}

Received: 8 April 2010/Accepted: 31 January 2011/Published online: 17 February 2011

(C) Springer-Verlag 2011

\begin{abstract}
In climate simulations we find a pronounced meridional (equator to pole) gradient of climate response to land cover change. Climate response approaches zero in the tropics, and increases towards the poles. The meridional gradient in climate response to land cover change results from damping feedbacks in the tropics, rather than from polar amplification. The main cause for the damping in the tropics is the decrease in cloud cover after deforestation, resulting in increased incoming radiation at the surface and a lower planetary albedo, both counteracting the increase in surface albedo with deforestation. In our simulations, deforestation was also associated with a decrease in sensible heat flux but not a clear signal in evaporation. Meridional differences in climate response have implications for attribution of observed climate change, as well as for climate change mitigation strategies.
\end{abstract}

Keywords Land use change - Deforestation - Climate response $\cdot$ Regional climate $\cdot$ Global climate model

M. K. van der Molen · B. J. J. M. van den Hurk .

W. Hazeleger

Royal Netherlands Meteorological Institute,

P.O. Box 201, 3730 AE De Bilt, The Netherlands

Present Address:

M. K. van der Molen ( $\square)$

Department of Meteorology and Air Quality,

Wageningen University and Research Centre (WUR),

Postbus 47, 6700 AA Wageningen, The Netherlands

e-mail: michiel.vandermolen@wur.nl

\section{Introduction}

The currently observed change in global mean temperature can be attributed to changes in the radiation balance of the earth as a result of anthropogenic changes in (a.o.) greenhouse gas concentration, aerosols and land cover (the socalled radiative forcing) and feedbacks of the climate system. The most important radiative forcing of land cover change is the change in albedo and the subsequent change in net radiation in relation to deforestation and/or afforestation. Land cover change has a distinct spatial distribution because of the regional differences in the need for agricultural lands in association with cultural history and the natural distribution of biomes over climate zones. Here we focus on the regional distribution of the feedbacks, of which the most important ones are the changes in evaporation and clouds.

Land cover has changed due to anthropogenic activity: from 1870 to 1992 the fraction of forests on land has decreased from 0.43 to 0.36 (Klein Goldewijk 2001; Ramankutty and Foley 1999, Section 2b), and still the deforestation continues at unprecedented rates. The corresponding increase in albedo has a negative radiative forcing (Forster et al. 2007) with a magnitude of roughly $20 \%$ of the radiative forcing of increased $\mathrm{CO}_{2}$ concentrations in the same period. For these reasons, land cover change is a matter of substantial interest in climate change studies.

The albedo change of land cover change and the associated change in temperature may provoke feedbacks leading to amplification or damping of the initial forcing of the climate system. Examples of mechanisms where feedbacks are involved are (1) the intimate link between land cover change, albedo and energy partitioning at the surface, implying a great potential to actively change boundary layer processes; (2) the impact of clouds on the radiation 
budget, which is large relative to the radiative forcings of land cover change and $\mathrm{CO}_{2}$. Changes in cloud formation may form an important feedback to land cover change, because the formation of clouds is connected to the surface fluxes of water vapour and sensible heat: the first is one of the sources of moisture and the second generates the vertical mixing affecting cloud formation. Such feedbacks and their spatial distribution determine the response of climate to the initial albedo change. The interactions between forcing and feedback make the use of complex earth system/climate models inevitable to quantify the climate response to land cover change.

A number of studies have used global circulation models (GCM's) to study land cover change, some focusing on the tropics (Polcher and Laval 1994; McGuffie et al. 1995; Zhang et al. 1996a, b) and some on the global changes (Zhao et al. 2001; Bounoua et al. 2002; Matthews et al. 2004; Feddema et al. 2005). Pitman et al. (2009) present a concise model intercomparison of the effects of land cover change in the context of the 'Land Use Change-IDentification of robust impacts' (LUCID) project. The same results contributed to LUCID are also analyzed in this paper.

We focus on the regional differences of climate response to land cover change, which have received little attention to date. Regional differences in climate response may have implications for future climate change projections, as well as for designing climate change mitigation strategies. In this perspective, it is the objective of this study to explore how the climate response to land cover change differs regionally in a climate model, and to explain this regional variation. We employ the General Circulation Model (GCM) called EC-Earth to estimate the climate response to land cover change on surface temperature, short- and longwave radiation, cloud cover, and sensible and latent heat fluxes.

\section{Methods}

To perform the simulations, the EC-Earth global circulation model is used (Haarsma et al. 2009; Hazeleger et al. 2010; see ecearth.knmi.nl). The model is a derivative of the Operational Seasonal Forecast System 3 of the Integrated Forecast System (IFS) of the European Centre for MediumRange Weather Forecasts (ECMWF). The atmospheric model version is very similar to IFS cycle $31 \mathrm{r} 1$, with spectral truncation T95 and 40 vertical levels. The ocean was represented by prescribed sea surface temperatures (SST) and sea-ice concentration (SIC), varying monthly and inter-annually after the Hadley Centre Ice and Sea Surface Temperature data set (Rayner et al. 2000, 2003). The global mean SST increased $0.33^{\circ} \mathrm{C}$ between the pre- industrial and present-day era, whereas the global mean SIC decreased $-0.6 \%$ (from 6.2 to $5.6 \%$ ) (Fig. 1).

Four experiments were performed, (1) a 'reference' (r) experiment, with pre-industrial (1870) land cover and $\mathrm{CO}_{2}$ concentration; (2) a 'modified vegetation' (v) experiment, where land cover was changed to the 1992 distribution (Fig. 2); (3) a 'modified $\mathrm{CO}_{2}$ concentration' (c) experiment, where $\mathrm{CO}_{2}$ concentration was changed to the 1992 level; and (4) a 'modified vegetation and $\mathrm{CO}_{2}$ concentration' (vc) experiment, where both land cover and $\mathrm{CO}_{2}$ concentration were changed to the present-day (1992) distribution/level. SST and SIC follow the $\mathrm{CO}_{2}$ concentration.

Each experiment consisted of 5 ensemble members of 10 -year duration. The ensemble members started in 1870 , $1875,1880,1885$ and 1890 for the ' $r$ ' and ' $v$ ' runs and in 1972, 1977, 1982, 1987 and 1992 for the 'c' and 'vc' experiments. Hence each experiment covers in total 30 years with overlapping ensemble members. In each ensemble member, the surface parameters and $\mathrm{CO}_{2}$ concentrations were set to their respective values in 1870 or 1972 and the atmosphere was always initialized as on 1 January 1990. The SST and SIC were initialised on the start date, and updated daily. The SST and SIC thus determine the difference between the ensemble members.
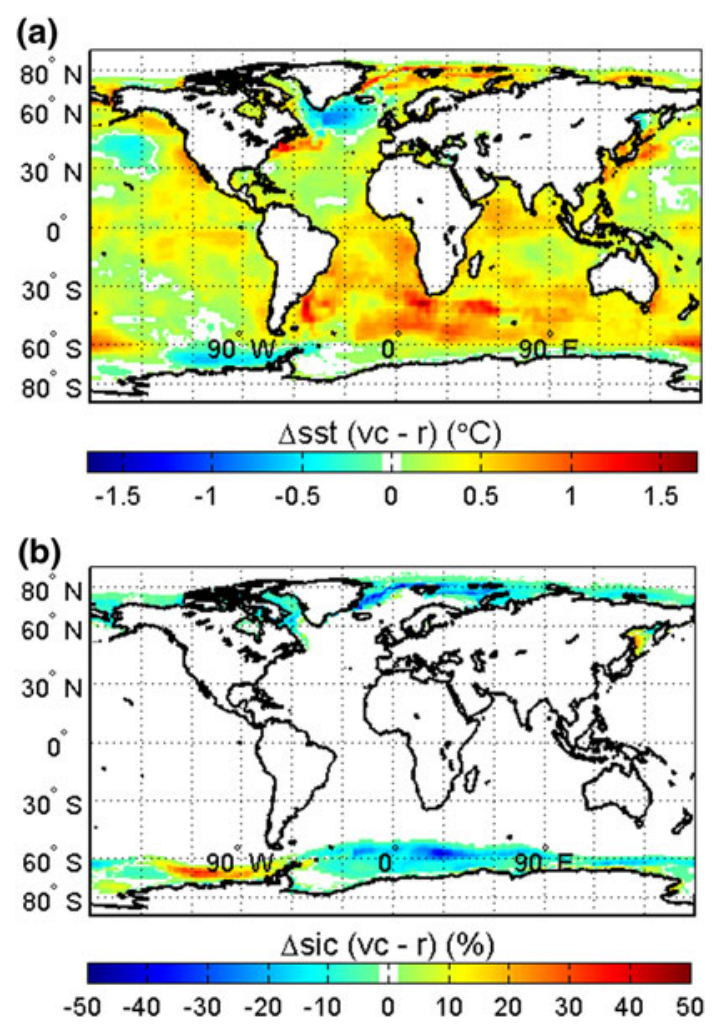

Fig. 1 Change in a SST and b SIC between the present-day and preindustrial experiments 
(a)

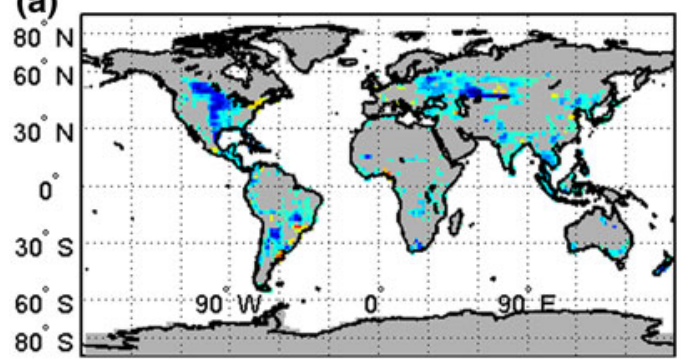

$\Delta$ forest cover $(\mathrm{v}-\mathrm{r})(\%)$

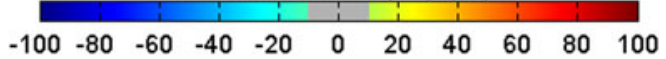

(b)

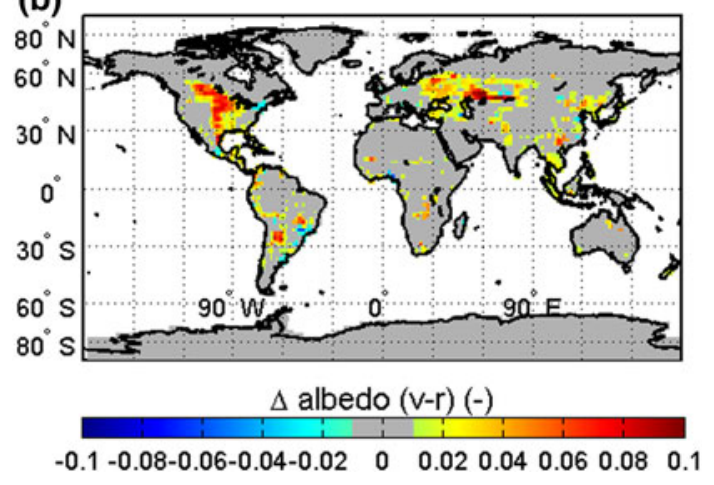

Fig. 2 Change in a the fraction of high vegetation (present-day-preindustrial) and $\mathbf{b}$ the resulting change in surface albedo. The change in the fraction of low vegetation (grasses, crops) is exactly opposite to the change in forest cover

We compared the temporal variability of soil moisture content within ensemble members with the variability between overlapping members to check for potential spin-up problems. As a reservoir soil moisture content acts as a form of memory to the atmosphere-land interaction. We used soil moisture because the memory makes the test more severe than it would be for atmospheric variables without memory. However, the match between soil moisture in overlapping members (e.g. the last 5 years of the member started in 1870 and the first 5 years of the member started in 1875) was generally good, and the difference smaller than the temporal variability within members. This result suggests that spin-up problems are not a major cause of concern. The initialisation in the month January resolves part of the spinup problems in many areas where land use change is large, because evaporation is small and precipitation dominates soil moisture recharge in the winter and spring. In the consideration to avoid spin-up problems or to increase the length of the time series, we therefore choose to use the complete time series in the analyses. The concentrations of $\mathrm{CH}_{4}, \mathrm{~N}_{2} \mathrm{O}, \mathrm{CFC} 11$ and $\mathrm{CFC} 12$ were changed in concert with the $\mathrm{CO}_{2}$ concentration changes.
Time series of the fractional cover of pasture and crops were obtained from Klein Goldewijk (2001) and Ramankutty and Foley (1999), respectively (Fig. 2), and implemented in the land surface scheme of EC-Earth. 20 different plant functional types are discerned, that are distributed into high and low vegetation types (Van den Hurk et al. 2000). Each grid cell is attributed only one dominant high vegetation type and one low vegetation type, with assigned fractions for each. The vegetation type determines vegetation characteristics such as leaf area index, surface roughness, minimum stomatal resistance and root depth. In the original setup, EC-Earth uses a satellite derived monthly background albedo map. However, in this study we want albedo to vary with prescribed (changes in) land use. Therefore we derived a look-up table for monthly and zonal mean albedo for each vegetation type as the limit to which the background albedo approaches when the vegetation fraction approaches $100 \%$. Using this look-up table, we were able to prescribe albedo maps compatible with the time varying vegetation fractions and with the original ECEarth background albedo map. In this setup, albedo is seasonally varying, but not interactive as in dynamic vegetation models. Table 1 indicates the typical EC-Earth albedo of 'high' and 'low' surface types and their relative distribution over the Earth in 1870 and 1992 according to Ramankutty and Foley (1999) and Klein Goldewijk (2001). Using this approach, land cover change caused a $1.4 \%$ increase in surface albedo over this period. The model output data are presented as temporal means on a $1^{\circ}$ by $1^{\circ}$ grid.

The Figs. 3, 4, 5, 6, 7, and 8 show the change of a number variables with the change in albedo in bins. The significance of the slope of the linear regression line through the raw data points has been tested using Student's $t$-test, and $\alpha$, the probability of exceedence, and $r^{2}$ are shown in the figures, both for the $\mathrm{NH}$ mid latitudes and the tropics.

Table 1 Land cover distribution and albedo in 1870 (the 'preindustrial' year in our simulations) and 1992 (the 'present-day' year in our simulations), and the corresponding weighted surface albedo

\begin{tabular}{llll}
\hline Surface type & Albedo & \multicolumn{2}{c}{ Surface fraction A.D. } \\
\cline { 3 - 4 } & & 1870 & 1992 \\
\hline Ocean & 0.07 & 0.72 & 0.72 \\
Low vegetation & 0.20 & 0.10 & 0.12 \\
High vegetation & 0.13 & 0.12 & 0.10 \\
Bare ground & 0.25 & 0.03 & 0.03 \\
Ice & 0.50 & 0.03 & 0.03 \\
Surface albedo & & 0.1087 & 0.1102 \\
\hline
\end{tabular}




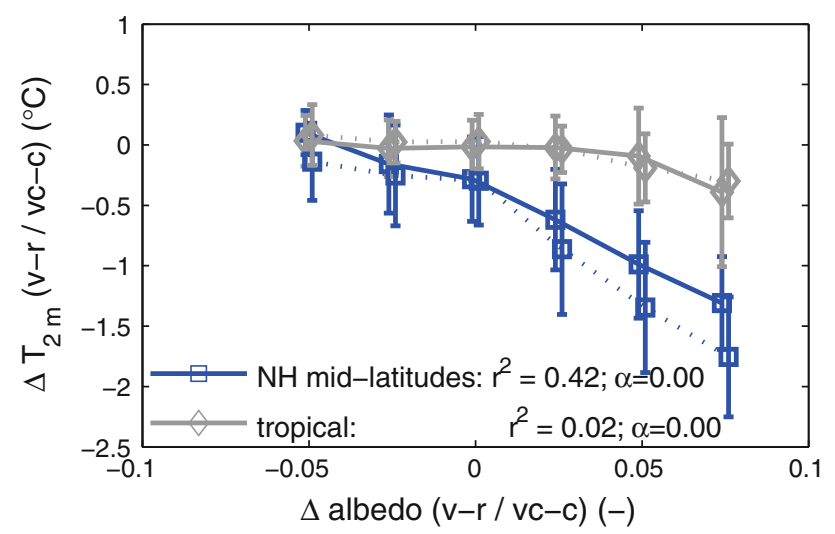

Fig. 3 The change in surface temperature as a function of change in albedo computed from the difference between the EC-Earth simulations at historic $\mathrm{CO}_{2}$ concentration ( $v-r$, solid lines) and at present-day $\mathrm{CO}_{2}$ concentration ( $v c-c$, dotted lines). The lines and markers represent the mean change in temperature for all gridpoints in the respective climate zone and class of albedo change, and the errorbars indicate the standard deviation over those gridpoints. The $\alpha$ values represent the probability of exceedence, indicating that the temperature trends for the $\mathrm{NH}$ mid latitudes and tropics are both tested significantly different from 0 with the Student $t$-test

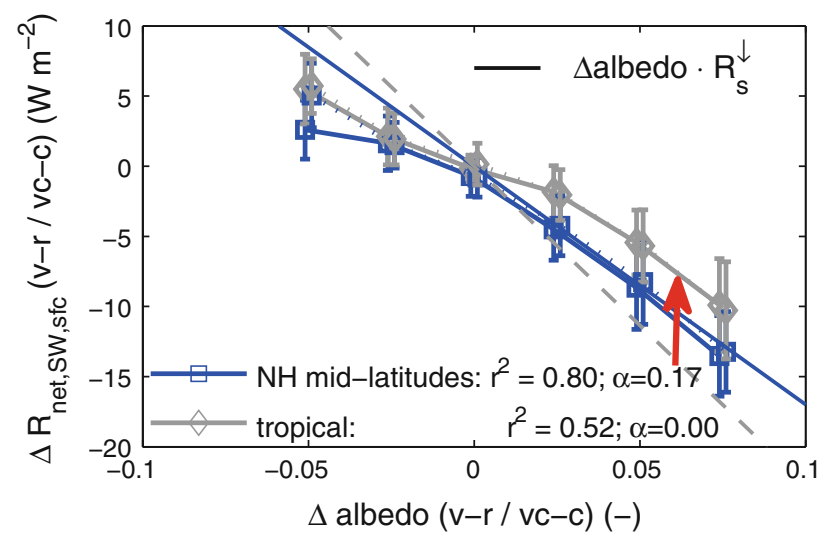

Fig. 4 The change in net shortwave radiation as a function of change in albedo computed from the difference between the EC-Earth simulations at historic ( $v-r$, solid lines) and at present-day $\mathrm{CO}_{2}$ concentration, SST and SIC ( $v c-c$, dotted lines). The thin lines without markers represent the direct shortwave radiative effect of albedo change: incoming SW radiation $\times(1-\Delta$ albedo $)$, thus including the effect of clouds in the reference simulation (solid: NH mid-latitudes, dashed: tropics). The deviation from the straight line (red arrow) indicates the impact of feedbacks. The figure applies to the surface, but is very similar for the TOA. The caption of Fig. 3 explains the errorbars

\section{Results}

\subsection{Temperature response}

Land cover change and the associated albedo change cause a change in the radiation balance of the Earth, with a consequent change in temperature. Figure 3 shows that
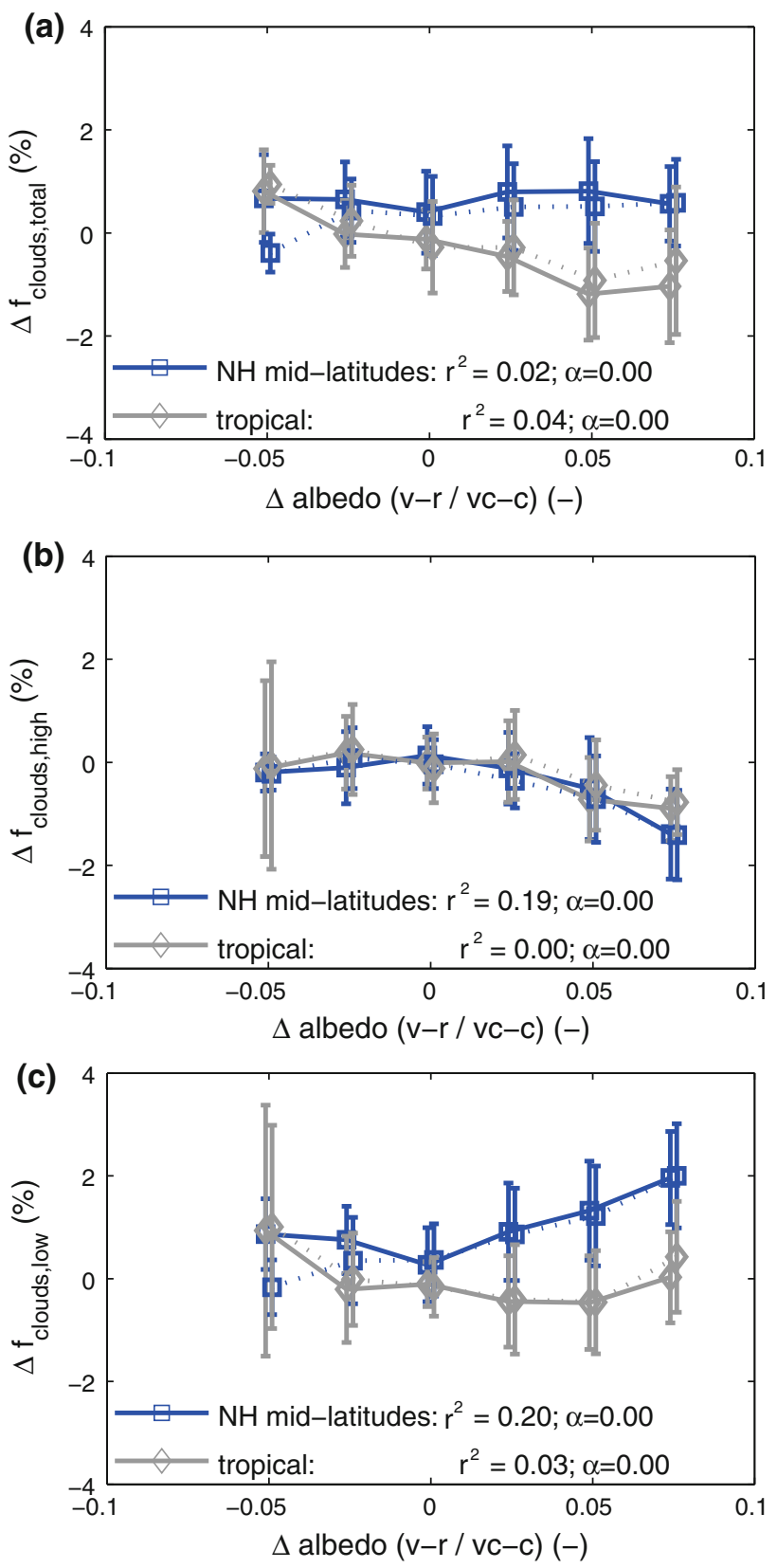

Fig. 5 The change in a total, $\mathbf{b}$ high and $\mathbf{c}$ low cloud cover fraction as a function of change in albedo computed from the difference between the EC-Earth simulations at historic $\mathrm{CO}_{2}$ concentration $(v-r$, solid lines) and at present-day $\mathrm{CO}_{2}$ concentration ( $v c-c$, dotted lines). The caption of Fig. 3 explains the errorbars

the temperature changes increase with the albedo changes. The temperature changes with albedo are larger in the Northern Hemispheric $(\mathrm{NH})$ mid-latitudes $\left(45-60^{\circ} \mathrm{N}\right)$ than in the tropics $\left(30^{\circ} \mathrm{S}-30^{\circ} \mathrm{N}\right)$. The grid cell average albedo changes in other climate zones are very small, which is why these zones are omitted in Fig. 3. The temperature responses are very similar in the simulations at historic (v-r) and present-day $\mathrm{CO}_{2}$ concentration and SST/SIC 

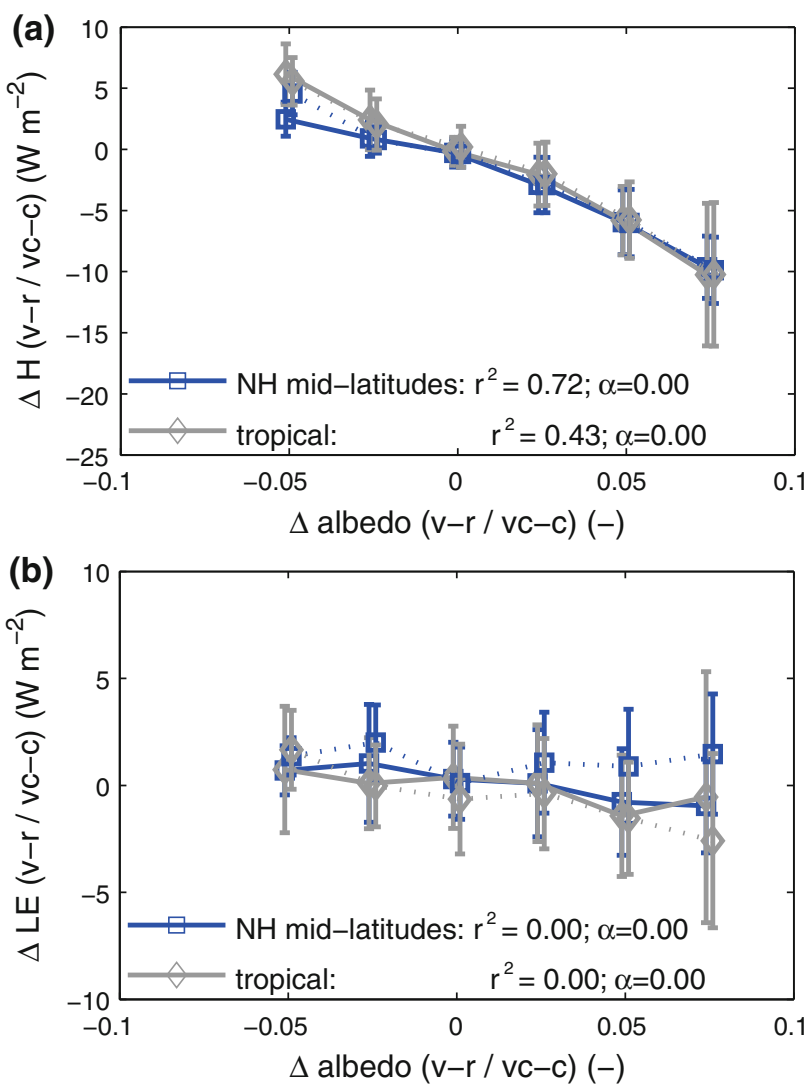

Fig. 6 The change in surface sensible a and latent $\mathbf{b}$ heat flux as a function of the change in computed as the difference between the ECEarth simulations at historic $\mathrm{CO}_{2}$ concentration $(v-r$, solid lines) and at present-day $\mathrm{CO}_{2}$ concentration ( $v c-c$, dotted lines). The caption of Fig. 3 explains the errorbars

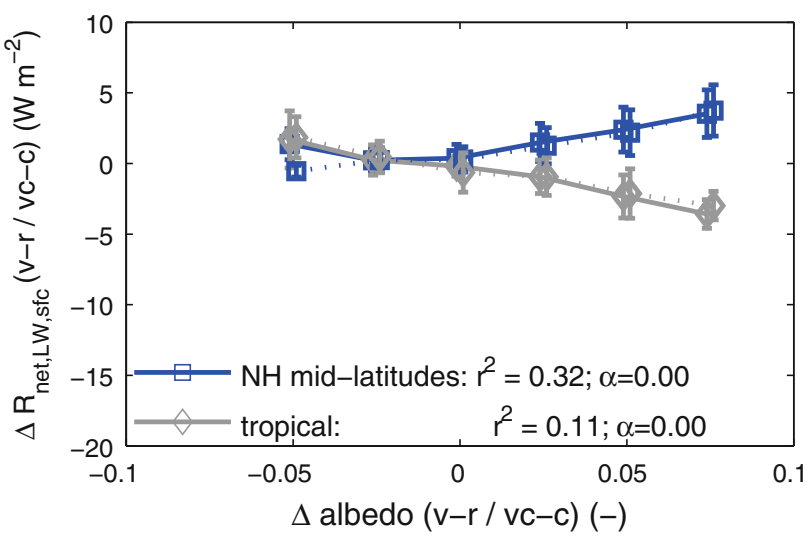

Fig. 7 The change in low cloud fraction as a function of the change in latent heat flux between the EC-Earth simulations at historic $\mathrm{CO}_{2}$ concentration $\left(v-r\right.$, solid lines) and at present-day $\mathrm{CO}_{2}$ concentration $(v c-c$, dotted lines). $\alpha$ indicates the exceedence probability of the slope of the linear regression line on the raw data. The caption of Fig. 3 explains the errorbars

(vc-c), which is a strong indication that different feedback mechanisms are acting in the mid-latitudes than in the tropics.

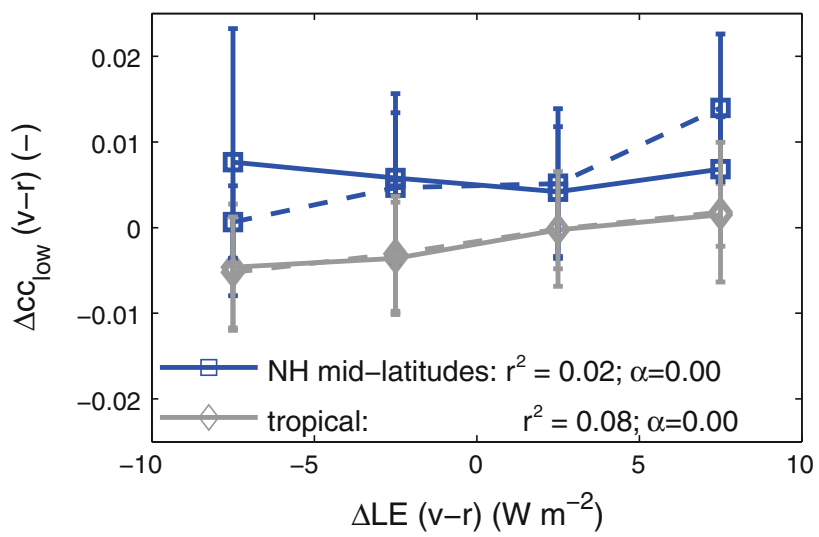

Fig. 8 The change in net longwave radiation as a function of the change in albedo computed as the difference between the EC-Earth simulations at historic $\mathrm{CO}_{2}$ concentration ( $v-r$, solid lines) and at present-day $\mathrm{CO}_{2}$ concentration ( $v c-c$, dotted lines). The caption of Fig. 3 explains the errorbars

\subsection{Shortwave radiation response}

The change in net shortwave radiation at the surface with a unit change of albedo depends on the global radiation, and is therefore strongly correlated with latitude. Figure 4 shows that the expected change in surface net radiation due to the albedo change (thin lines) is larger in the tropics than in the mid-latitudes due to the larger amounts of global radiation. In contrast to the expected change in net radiation, the actual change in net radiation is smaller in the tropics than in the mid-latitudes. Apparently there is a strong damping feedback mechanism acting in the tropics. In the mid-latitudes, the change in net radiation resembles the radiative forcing, suggesting the absence of (net) feedbacks.

\subsection{Cloud feedback}

The damping feedback in the tropics is explained by a regional decrease in total cloud cover (Fig. 5a): at the top of the atmosphere (TOA) the reduced cloud cover results in a lower Earth albedo, counteracting the increasing albedo at the surface. At the surface the same reduced cloud cover increases the incoming and net shortwave radiation, thus counteracting the effect of the albedo increase. Figure 5a shows that the cloud cover indeed decreased in the tropics by about $1 \%$ in the ' $\mathrm{v}-\mathrm{r}$ ' and ' $\mathrm{vc}-\mathrm{c}$ ' simulations, whereas it increased slightly in the $\mathrm{NH}$ mid-latitudes.

In the tropics, the decrease in total cloud fraction is primarily caused by the reduction in high clouds (higher than $6-7 \mathrm{~km}$, Fig. $5 \mathrm{~b}$ ), whereas the fraction of low clouds (lower than about $2 \mathrm{~km}$, Fig. 5c) does not change much. In the mid-latitudes, the slight increase in total cloud fraction is the net effect of a shift from high clouds to low clouds (Fig. 5b, c). Ignoring possible effects of cloud overlap, the 
effects of the general decrease in total cloud cover explain the relatively small compensation of surface shortwave radiation in response to surface albedo changes.

\subsection{Surface heat fluxes}

Figure 6 shows that the sensible heat flux $(\mathrm{H})$ is reduced both in the tropics and in the mid-latitudes by a maximum of about $10 \mathrm{~W} \mathrm{~m}^{-2}$, which is in the same order as the reduction in net shortwave radiation. There is a slight decrease in latent heat flux (LE) in the tropics $\left(1-3 \mathrm{~W} \mathrm{~m}^{-2}\right)$ at historic $\mathrm{CO}_{2}$ concentrations. This has mixed effects on the lifting condensation level (LCL) and cloud cover: the LCL decreases with the smaller $\mathrm{H}$, but increases with smaller LE; the smaller $\mathrm{H}$ may cause the boundary layer to be shallower, so that convection may not be able to reach the LCL. As a consequence, the changes in low cloud cover are small particularly in the tropics. However, the changes in evaporation are smaller at present day than at preindustrial $\mathrm{CO}_{2}$-concentrations, implying that this feedback is not very robust.

Apparently there is not a strong relation between the change in albedo and the change in latent heat flux, which would make it hard to explain why the cloud fraction changes in the tropics, and not in the $\mathrm{NH}$ mid-latitudes. However, Fig. 7 shows that the latent heat flux is stronger correlated to low cloud cover in the tropics than in the $\mathrm{NH}$ mid-latitudes. This implies that a drop in albedo causes quite variable responses on LE (Fig. 6b), but the resulting change in LE nevertheless explains to a certain degree the change in low cloud fraction, in the tropics. The variable response of LE to albedo may be expected, because LE does not only depend on albedo, but also in available energy, vapour pressure deficit and soil moisture. It may also be expected that the response of low clouds to LE is stronger in the tropics than in the mid-latitudes, because in the tropics clouds are more often caused by local convection and in the mid-latitudes clouds are more often caused by synoptic weather systems.

As a result of the changed surface temperatures and cloud fractions, the net longwave radiation also changes, with distinct differences between the $\mathrm{NH}$ mid-latitudes and the tropics (Fig. 8). The changes in longwave radiation are as expected from the change in cloud cover, and oppose the effect of cloud cover on shortwave radiation.

\subsection{Zonal mean climate response}

As a result of the different feedbacks, the climate response $\Delta \mathrm{T}$ is not homogenously distributed over the globe (Fig. 9a). Here the climate response is scaled with $\Delta$ albedo, to account for the varying degree of land cover change. A strong latitudinal gradient is observed, where climate response $\Delta \mathrm{T} / \Delta$ albedo is nearly zero in the tropics and increasing to a (negative) maximum in the mid-latitudes. This is also clearly visible in the zonal mean climate response (Fig. 9b).

The values presented in Fig. 9a represent the average local climate response over the land area where the albedo change is larger than \pm 0.002 (this lower limit in albedo change is required to obtain a stable ratio). The local approach gives an underestimation of the climate response, because advection and feedback propagation may cause temperature changes in neighbouring gridpoints. Figure $9 \mathrm{~b}$ also shows the non-local zonal mean climate response computed as the ratio of the zonal average temperature change and the zonal average albedo change for all gridpoints over land, thus including non-local temperature changes. This non-local climate response is indeed somewhat larger (more negative, Fig. 9b).
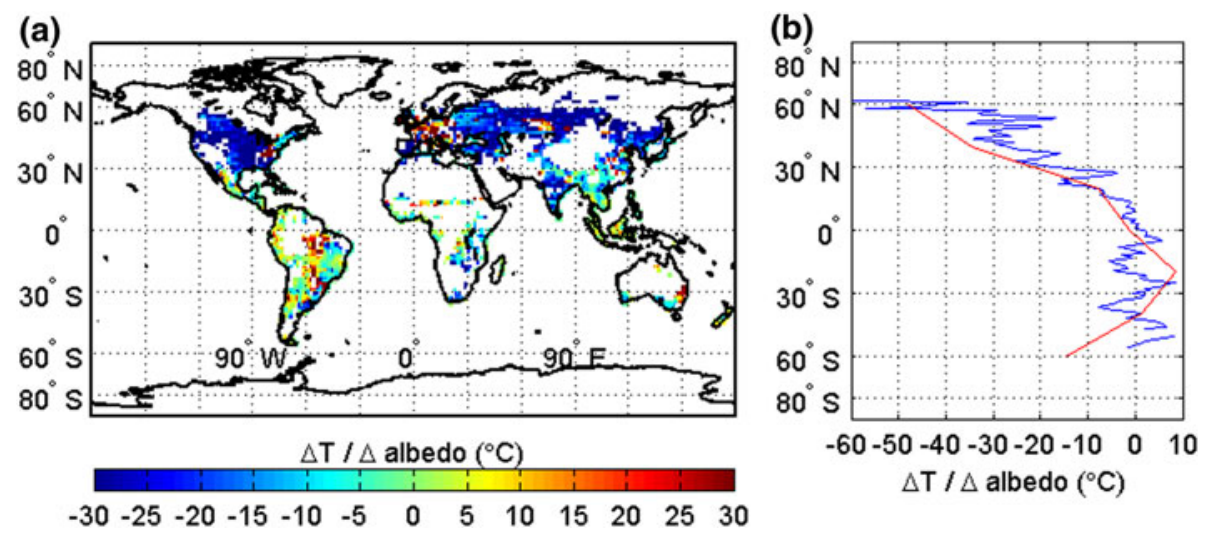

Fig. 9 a Spatial distribution of climate response to land cover change, scaled with the albedo change. Albedo change and temperature response are computed on a monthly basis and displayed as annual mean. Areas where the albedo change is less than 0.002 are masked out b zonal average climate response: the blue line represents the zonal average of the numbers displayed in (a), and the red line represents the ratio of the zonal average $\Delta \mathrm{T}$ and the zonal average $\Delta$ albedo for all gridpoints over land, thus including non-local temperature changes, over latitudinal bands of $20^{\circ}$ to reduce crosszonal temperature advection 


\section{Discussion}

It is known that the climate response to a given radiative forcing may depend on the characteristics in terms of nature, latitude, and altitude of the forcing (cf. Hansen et al. 1997; Harvey 2000; Boer and Yu 2003a, b). However, to our knowledge the distinct meridional gradient in climate response to land cover change has not been reported earlier. The meridional gradient in climate response to land cover change has implications for explaining observed temperature changes in regions affected by land cover change. It also impacts the efficiency of aforestation programs aimed at mitigating climate warming by sequestering carbon dioxide from the atmosphere. Our model results suggest that aforestation is accompanied in the NH mid-latitudes with climate warming, whereas it is nearly temperature neutral in the tropics (apart from the effect of the mitigated greenhouse gas effect). Bonan (2008) also discusses the meridional differences of climate impact of forests, and argues that the most important biophysical impacts of tropical and boreal forests are evaporative cooling and warming by snow masking, respectively. The negative radiative forcing of deforestation would thus be accompanied by warming feedbacks in the tropics and cooling feedbacks in the northern latitudes. This is consistent with our results, although we do not find substantial changes in LE in the tropics, or amplified changes in albedo in the boreal zone.

The term 'polar amplification' is often used in global warming studies to emphasize that global warming due to the enhanced greenhouse gas effect is amplified towards the poles as a result of the snow-albedo feedback. In the case presented here it is more appropriate to use the term 'tropical damping', because there is no evidence of the presence of amplifying feedbacks in the $\mathrm{NH}$ mid-latitudinal shortwave radiation, whereas there is evidence of damping feedbacks in the tropics (Figs. 4, 5).

The evidence of the damping feedback in the tropics is most convincingly seen in Fig. 4, showing that the actual decrease in net shortwave radiation with albedo increase is much smaller than expected. This can only be explained by an increase in incoming shortwave radiation, which must be related to a reduction in cloud fraction. The large standard deviations in the $\Delta \mathrm{LE}$ (Fig. 6b) show that there is quite some variation, suggesting that the general trend of decreased cloud cover reflects the net balance of the varying influences of Bowen ratio, convection strength and boundary layer height. However, there is a stronger relation between the change in LE and the low cloud fraction (Fig. 7).

Two potential explanations for the difference between 'polar amplification due to the enhanced greenhouse gas effect' and 'tropical damping due to land cover change' are
(1) that the majority of land cover change does not extend far enough to the North for the snow-albedo feedback to have a pronounced effect in areas affected by land cover change, and (2) that the climate response to land cover change has a pronounced diurnal cycle, in concert with global radiation, and therefore has a great potential to affect convective cloud development (Fig. 5). The greenhouse gas effect in contrast has no pronounced diurnal cycle. The latitudinal gradient of global radiation does not explain the observed meridional gradient in climate response, because the larger amount of global radiation towards the tropics would be expected to increase the radiative forcing and climate response, which is opposite to our model results.

The specific LUCID experimental setup (Pitman et al. 2009) with fixed SST and SIC suppresses temperature changes over the ocean in response to vegetation change. The fixed SST and SIC in practice turn the oceans into potentially unlimited sources or sinks of heat and moisture. This is illustrated by the changes in net oceanic surface sensible and latent heat fluxes in response to land cover change: $\Delta \mathrm{H}=+0.017 \mathrm{~W} \mathrm{~m}^{-2}$ and $\Delta \mathrm{LE}=+0.033$ $\mathrm{W} \mathrm{m}{ }^{-2}$. The oceanic heat release is a response to the cooling of the atmosphere, demonstrating that LCC induced cooling has non-local effects on the energy balance, although the ocean temperature does not respond in this experimental setup. However, further studies with coupled ocean models are foreseen. Pitman et al. (2009) show that in the LUCID model intercomparison, EC-Earth is among the three models with the strongest temperature changes. Like EC-Earth, every participating model has the most pronounced temperature changes in the $\mathrm{NH}$ midlatitudes.

Pitman et al. (2009) emphasize that the choices in the surface/vegetation model formulation with respect to shortterm variation in surface conductance of water vapour and heat, and particularly to seasonal variation in surface roughness, leaf area index and phenology, as well as the parameterization of different (agricultural) vegetation types has important implications for the model's climate sensitivity to land cover change. In this respect, EC-Earth, with seasonally fixed roughness and leaf area index and uniform soil types across the globe (van den Hurk et al. 2000) currently takes a middle position considering complexity among the 4 models without dynamic vegetation participating in LUCID. However, the response of latent heat flux (LE) to land cover change appears quite contrasting between the models: some models simulate decreasing LE after deforestation in all climate zones (IPSL, CCAM, SPEEDY), one model simulates increasing LE (CCSM) and other models simulate mixed and/or meridionally varying responses (ARPEGE, ECHAM5, EC-Earth). Pitman et al. (2009) argue that there is no agreed upon best 
practice or large-scale calibration protocol, and as a result the climate response to land cover change depends on the model formulation.

In South America a contrasting climate response pattern appears as a function of continentality, with cooling near the coast and warming further inland (Fig. 8a). This shows that different feedbacks mechanisms are active. In continental conditions these are often related to cloud cover (convective or stratiform) and water vapour recycling, and in maritime conditions often related to sea breezes (van der Molen et al. 2006).

\section{Conclusions}

Simulations with the EC-Earth climate model indicate a strong meridional gradient in climate response to land cover change: the climate response is nearly zero in the tropics and increases towards the NH mid-latitudes. Classical theory is that climate warming amplifies towards the poles, because of the snow-albedo feedback. However, in our simulations, the change in net radiation resembles the radiative forcing in the $\mathrm{NH}$ mid-latitudes, whereas it is much smaller in the tropics. This indicates that (net) damping feedbacks are present in the tropics, but not in the $\mathrm{NH}$ mid-latitudes. We show that in our model a decrease in cloud cover after deforestation is responsible for this 'tropical damping'.

Distinguishing meridional differences in climate response to land cover change is important for attribution of climate change, and may have implications for the effectiveness of aforestation programs to mitigate climate change due to increasing $\mathrm{CO}_{2}$ concentrations. Simulations of the impact of land cover change on climate by different climate models often provide contrasting results, as a consequence of defensible differences in model formulations. The climate response is a useful parameter for climate model intercomparisons, and we aim to contribute to such intercomparisons with this publication.

Acknowledgments We thank Xueli Wang for her help setting up the experiments. The organizers of the LUCID campaign are acknowledged, in particular Nathalie de Noblet, Andy Pitman and Faye Cruz. The Dutch Research Organization (NWO) sponsored parts of this study.

\section{References}

Boer GJ, Yu B (2003a) Climate sensitivity and response. Clim Dyn 20:415-429. doi:10.1007/s00382-002-0283-3

Boer GJ, Yu B (2003b) Climate sensitivity and climate state. Clim Dyn 21:167-176. doi:10.1007/s00382-003-0323-7

Bonan GB (2008) Forests and climate change: forcings, feedbacks and climate benefits of forests. Science 320:1444-1449
Bounoua L, Defries R, Collatz GJ, Sellers P, Kahn H (2002) Effects of land cover conversion on surface climate. Clim. Chang 52:29-64

Feddema JJ, Oleson KW, Bonan GB, Mearns LO, Buja LE, Meehl GA, Washington WM (2005) The importance of landcover change in simulating future climates. Science 310:16741678

Forster P, Ramaswamy V, Artaxo P, Berntsen T, Betts R, Fahey DW, Haywood J, Lean J, Lowe DC, Myhre G, Nganga J, Prinn R, Raga G, Schulz M, van Dorland R (2007) Changes in atmospheric constituents and in radiative forcing. In: Solomon S, Qin D, Manning M, Chen Z, Marquis M, Averyt KB, Tignor M, Miller HL (eds) Climate change 2007: the physical basis, contribution of Working group I to the fourth assessment report of the Intergovernmental Panel of Climate Change. Cambridge University Press, Cambridge, pp 129-234

Haarsma RJ, Selten FM, van den Hurk BJJM, Hazelegeren W, Wang X (2009) Drier mediterranean soils due to greenhouse warming bring easterly winds over summertime central europe. Geophys Res Lett 36:L04705. doi:10.1029/2008GL036617

Hansen J, Sato M, Ruedy R (1997) Radiative forcing and climate response. J Geophys Res 102(6):6831-6864

Harvey LDD (2000) Global warming, the hard science. Prentice-Hall, Harlow

Hazeleger W, Severijns C, Semmler T, Stefanescu S, Yang S, Wang X, Wyser K, Baldasano JM, Bintanja R, Bougeault P, Caballero R, Dutra E, Ekman AML, Christensen JH, van den Hurk B, Jimenez P, Jones C, Kallberg P, Koenigk T, McGrath R, Miranda P, van Noije T, Parodi JA, Schmith T, Selten F, Storelvmo T, Sterl A, Tapamo H, Vancoppenolle M, Viterbo P, Willen U (2010) EC-EARTH: a seamless earth system prediction approach in action. Bull Am Meteorol Soc 91:1357-1363. doi 10.1175/2010BAMS2877.1

Klein Goldewijk K (2001) Estimating global land-use change within the past 300 years: the HYDE database. Glob Biogeochem Cycl $15: 417-433$

Matthews HD, Weaver AJ, Meissner KJ, Gillett NP, Eby M (2004) Natural and anthropogenic climate change: incorporating historical land cover change, vegetation dynamics and the global carbon cycle. Clim Dyn 22:461-479

McGuffie K, Henderson-Sellers A, Zhang H, Durbidge TB, Pitman AJ (1995) Global climate sensitivity to tropical deforestation. Glob Plan Chang 10:97-128

Pitman AJ, de Noblet-Ducoudré N, Cruz FT, Davin EL, Bonan GB, Brovkin V, Claussen M, Delire C, Ganzeveld L, Gayler V, van den Hurk BJJM, Lawrence PJ, van der Molen MK, Müller C, Reick CH, Seneviratne SI, Strengers BJ, Voldoire A (2009) Land-use and climate via the LUCID intercomparison study: implications for experimental design in AR5. Geophys Res Lett 36:L14814. doi:10.1029/2009GL039076

Polcher J, Laval K (1994) The impact of African and Amazonian deforestation on tropical climate. J Hydrol 155:389-405

Ramankutty N, Foley JA (1999) Estimating historical changes in global land-cover: cropslands from 1700 to 1992. Glob Biogeochem Cycl 13:97-1027

Rayner NA, Parker DE, Horton EB, Folland CK, Alexander LV, Frich $P$ (2000) The HadISST1 global sea-ice and sea surface temperature dataset, 1871-1999. Hadley Center Technical Note 17. Exeter, UK

Rayner NA, Parker DE, Horton EB, Folland CK, Alexander LV, Rowell D, Kent EC, Kaplan A (2003) Global analyses of sea surface temperature, sea ice, and night marine air temperature since the late nineteenth century. J Geophys Res 108:4407. doi: 10.1029/2002JD002670

Van den Hurk BJJM, Viterbo P, Beljaars ACM, Betts AK (2000) Offline validation of the ERA40 surface scheme. ECMWF 
TechMemo 295; see http://www.ecmwf.int/publications/library/ ecpublications/pdf/tm/001-300/tm295.pdf. Reading, UK

Van der Molen MK, Dolman AJ, Waterloo MJ, Bruijnzeel LA (2006) Climate is affected more by maritime than by continental land use change: a multiple scale analysis. Glob Plan Chang 54(1-2):128-149. doi:10.1016/j.gloplacha.2006.05.005

Zhang H, Henderson-Sellers A, McGuffie K (1996a) Impacts of tropical deforestation. Part I: Process analysis of local climatic change. J Clim 9:1497-1517
Zhang H, McGuffie K, Henderson-Sellers A (1996b) Impacts of tropical deforestation. Part II: The role of large-scale dynamics. J Clim 9:2498-2521

Zhao M, Pitman AJ, Chase T (2001) The impact of land cover change on the atmospheric circulation. Clim Dyn 17:467-477 